\title{
COMPARISON OF X-BAND, L-BAND AND C-BAND RADAR IMAGES FOR MONITORING SUBSIDENCE IN AGRICULTURAL REGIONS
}

\author{
Mahdi Motagh $^{(1)}$, Mahmud Haghshenas Haghighi ${ }^{(1)}$, Roghaye Shamshiri ${ }^{(2)}$, Mustapha Esmaeili ${ }^{(3)}$ \\ (1) GFZ German Research Center for Geosciences, Potsdam, Germany. Email: Motagh@gfz-potsdam.de \\ (2) Norwegian University of Science and Technology, Norway.Email: roghayeh.shamshiri@ntnu.no \\ (3) Department of surveying and Geomatics Engineering, University of Tehran, Iran. Email: mostafaesi@gmail.com
}

\begin{abstract}
The ongoing pattern of groundwater induced land subsidence in major valleys and agricultural regions of Iran has been recently documented by several studies (e.g. [1-4]) using C-band Interferometric Synthetic Aperture Radar (InSAR) observations. In this article we present the results of our research in which we evaluated the performance of C-band, L-band and Xband SAR data, using time-series method of small baseline subset (SBAS), to retrieve long time series of ground subsidence in agricultural regions in the country. Two major groundwater basins have been selected for this purpose: (1) Rafsanjan Valley in the Kerman province of central Iran and (2) Tehran Plain (capital of Iran). We also report on our experience using dualpolarimetry (HH/VV) X-band SAR data for Persistent Scatterer (PS) deformation analysis in natural terrains subject to high rate of deformation.
\end{abstract}

\section{Land subsidence in Rafsanjan}

To investigate land subsidence in Rafsanjan we utilized 3 sets of images, including 12 Envisat ASAR data in a descending track covering March 2004-June 2006, 23 Envisat ASAR data in an ascending track covering June 2004-August 2007, and 10 ALOS PALSAR data in an ascending track covering December 2007-November 2010. The outline of the SAR frames has been illustrated in Fig. 1. We processed all SAR data with small baseline subset (SBAS) approach implemented in StaMPS software (http://homepages.see.leeds.ac.uk/ earahoo/stamps/inde x.html).

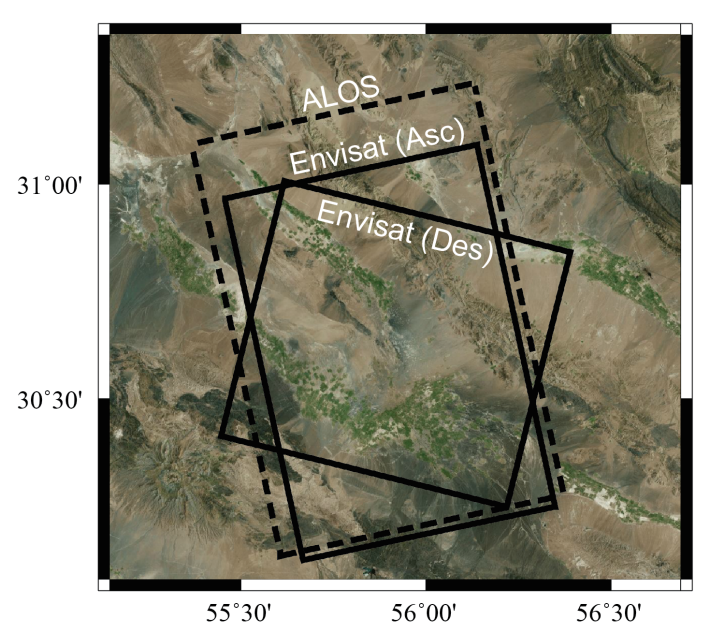

Figure 1. Geographic location of the Rafsanjan valley in central Iran. Rectangles show the frames of radar sensors used in this study.

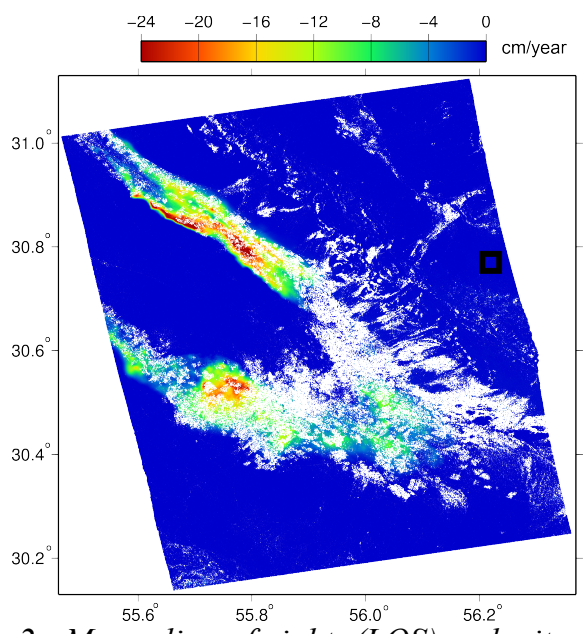

Figure 2. Mean line-of-sight (LOS) velocity derived from Envisat ascending data. The black square is the reference area. 


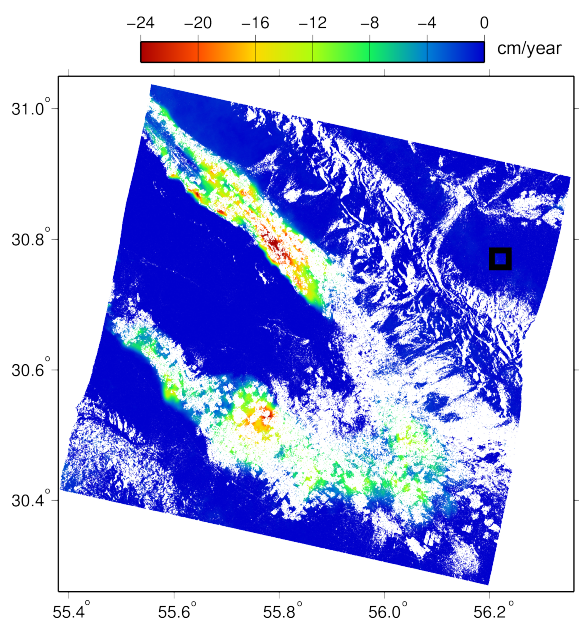

Figure 3. Mean line-of-sight (LOS) velocity derived from Envisat descending data.

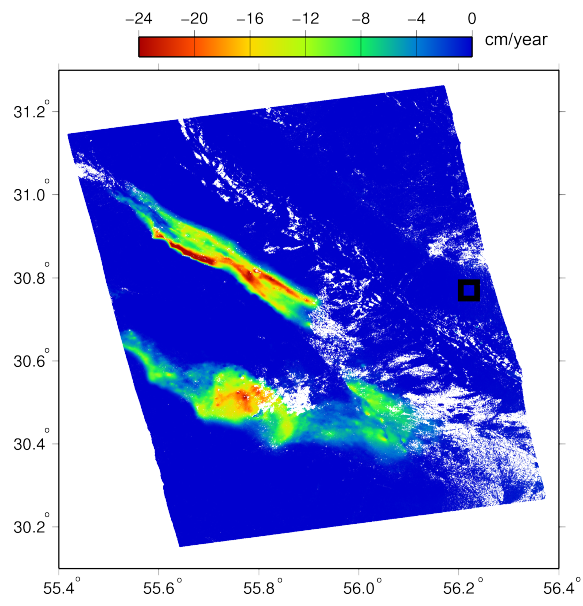

Figure 4. Mean line-of-sight (LOS) velocity derived from ALOS ascending data

Figs. 2-4 depict the mean line-of-sight (LOS deformation maps in the year 2004-2007 derived from Envisat ascending (Fig. 2) and Envisat descending data (Fig. 3) and in the year 2007-2010 derived from ALOS ascending data (Fig. 4). As seen in Figs. 2-4 the entire Rafsanjan valley has been affected by land subsidence with maximum rate of LOS motion reaching to 25 $\mathrm{cm} /$ year. The difference in the rate and pattern of LOS displacement maps between ascending and descending results can be attributed to the effect of horizontal motion.

\section{Land subsidence in Tehran}

The analysis in this section has been divided into two parts. First we compare using SBAS approach timeseries results from different sensors to retrieve spatiotemporal pattern of land subsidence west of Tehran. The data include 39 C-band Envisat ASAR, 10 L-band
ALOS PALSAR, and $15 \mathrm{X}$-band TerraSAR-X copolarized (VV) data. Secondly, we evaluate the use of polarimetric optimization method using dual-polarized data for Persistent Scatterer (PS) analysis in the same region. Our dual-polarimetry dataset includes $17 \mathrm{X}$ band SAR data (HH/VV) over southwest of Tehran acquired by the TerraSAR-X satellite between July 2013 and January 2014.

\subsection{Multi-sensor InSAR survey}

Underground water exploitation in Tehran Plain has led to land subsidence in agricultural areas west of Tehran City $[1,4]$. Here we present the result of InSAR timeseries processing applied on a large dataset of X-band, C-band and L-band SAR imagery covering a long period of time between 2003 and 2013. Average velocity maps in the vertical direction, assuming no contribution from horizontal motion in the LOS direction, derived from different datasets are shown in Fig. 5. The spatial extent of the subsidence area is almost similar in the results obtained from different sensors (Fig. 5). However, densities of coherent pixels in TSX results are more than other datasets. Although short wavelength X-band SAR data are more sensitive to vegetation coverage and temporal decorrelation than C-band and L-band data, time interval between two consecutive TSX images are short enough (11 day) to derive coherent interferograms for deformation analysis in agricultural regions with large rate $(>20 \mathrm{~cm} / \mathrm{yr})$ of deformation. Density of coherent pixels in C-band Envisat results is less than other datasets.

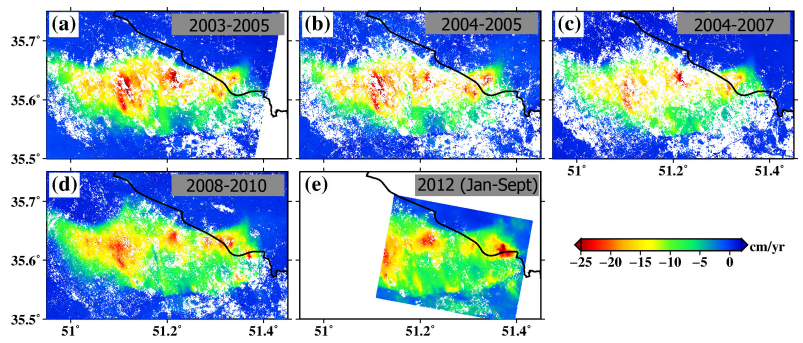

Figure 5. Average vertical velocity maps derived from different datasets for the subsidence bowl southwest of Tehran City. (a) Envisat 149, (b) Envisat 378, (c) Envisat 414, (d) ALOS, and (e) TSX. Black line shows the boundary of the urban and residential area in Tehran.

\subsection{Dual-polarimetry analysis}

Using dual polarimetric SAR data we can produce for each pixel in a SAR image a scattering coefficient, $\mu$, defined as

$$
\mu_{i}=\omega_{i}^{* T} \underline{K}_{i}
$$

where 


$$
\underline{\omega}=\left[\cos (\alpha), \sin (\alpha) e^{j \psi}\right]^{T},\left\{\begin{array}{c}
0 \leq \alpha \leq \pi / 2 \\
-\pi \leq \psi \leq \pi
\end{array}\right.
$$

and

$$
\underline{K}=\frac{1}{\sqrt{2}}\left[S_{h h}+S_{v v}, S_{h h}-S_{v v}\right]^{T}
$$

* in (1) represents the conjugate operator, $\omega$ is the projection vector and $K$ is the vectorized scattering matrix.

Ferretti et al. (2001) presented an index called Amplitude Dispersion Index $\left(D_{A}\right)$ that can be employed for the estimation of the phase stability in scatterers with high values of SNR [5]. ADI is defined as

$$
D_{A}=\frac{\sigma_{a}}{\bar{a}}
$$

Where $\sigma_{a}=\frac{1}{\sqrt{N}} \sqrt{\sum_{i=1}^{N}\left(\left|s_{i}\right|-\bar{s}\right)^{2}}$ stands for the standard deviation of amplitude, $\bar{a}=|\bar{s}|=\frac{1}{N} \sum_{i=1}^{N}\left|s_{i}\right|$ is the mean amplitude and $\mathrm{N}$ is number of images. For dual polarimetry observations this criteria is reduced to

$$
D_{A}^{2}=\frac{\sum_{i=1}^{N}\left|\omega^{{ }^{*} T} \underline{K}_{i}\right|^{2}}{\left(\sum_{i=1}^{N}\left|\omega^{{ }^{*} T} \underline{K}_{i}\right|\right)^{2}}
$$

Now the issue is to find the projection vector providing the optimum value of $D_{A}$. Practically this approach consists of performing, for each pixel, a grid search over the whole polarimetric space in order to find the proper projection vector $(\alpha$ and $\psi$ ) that minimizes ADI and therefore maximizes the possibility of a pixel to be as a PS candidate (PSC). After selecting initial PS candidates, we then use the method presented by [6] to find the final set of pixels for deformation analysis.

Fig. 6 illustrates comparison between the results of single-pole (HH and VV) and optimum polarization PS analysis for the agricultural region west of Tehran. As seen in Fig. 6 the density of PS pixels in optimum polarization channel has increased, in particular in regions with high rates of deformation. The number of PS pixels in HH and VV channels are approx. 1260000 and 1219000 respectively, while by applying PSInSAR on optimum polarization channel the number increases up to $45-50 \%$.
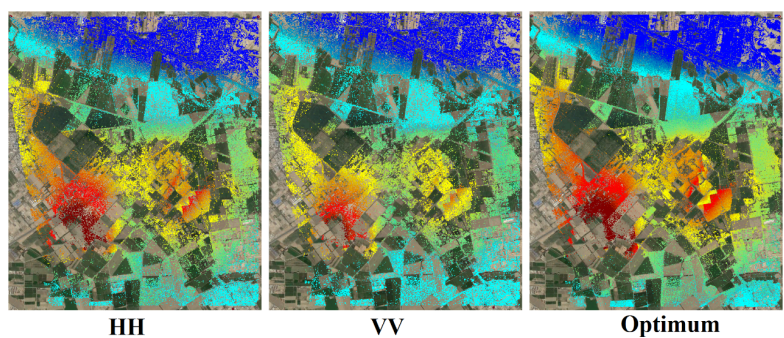

Fig. 6. Results of PS analysis for $\mathrm{HH}, \mathrm{VV}$ and optimum polarization.

\section{ACKNOWLEDGMENTS}

TerraSAR-X original data is copyright 2010-2011 DLR and was provided under PI projects GEO0179 \& XTI_LAND0505. We thank European Space Agency for providing Envisat and ALOS data via catgory-1 proposals AOALO3740 and C1P2892.

\section{REFERENCES}

1. Motagh, M., Walter, T. R., Sharifi, M. A., Fielding,E., Schenk, A., Anderssohn, J., \& Zschau, J. (2008). Land subsidence in Iran caused by widespread water reservoir overexploitation. Geophysical Research Letters, 35(16).

2. Motagh, M., Djamour, Y., Walter, T. R., Wetzel, H. U., Zschau, J., \& Arabi, S. (2007). Land subsidence in Mashhad Valley, northeast Iran: results from InSAR, levelling and GPS. Geophysical Journal International, 168(2), 518526.

3. Dehghani, M., Zoej, M. J. V., Entezam, I., Mansourian, A., \& Saatchi, S. (2009). InSAR monitoring of progressive land subsidence in Neyshabour, northeast Iran. Geophysical Journal International, 178(1), 47-56.

4. Sadeghi, Z., Valadan Zoej, M. J., \& Dehghani, M. (2013). An improved persistent scatterer interferometry for subsidence monitoring in the Tehran basin. Selected Topics in Applied Earth Observations and Remote Sensing, IEEE Journal of, 6(3), 1571-1577.

5. Ferretti, A., Prati, C., \& Rocca, F. (2001). Permanent scatterers in SAR interferometry. Geoscience and Remote Sensing, IEEE Transactions on, 39(1), 8-20.

6. Hooper, A., Zebker, H., Segall, P., \& Kampes, B. (2004). A new method for measuring deformation on volcanoes and other natural terrains using InSAR persistent scatterers. Geophysical research letters, 31(23), DOI: 10.1029/2004GL021737 